\title{
Analysis of Women Participation in Indian Agriculture
}

\author{
${ }^{1}$ Dr. Mun Mun Ghosh, ${ }^{2}$ Dr. Arindam Ghosh \\ ${ }^{I}$ Assistant Professor, Symbiosis Institute of Media \& Communication (SIMC) Lavale, Pune, Maharashtra, India \\ ${ }^{2}$ Assistant Professor, MIT- COE, CMSR, Kothrud, Pune, Maharashtra, India
}

\begin{abstract}
Agriculture sector as a whole has developed and emerged immensely with the infusion of science and technology. But this latest emergence is not capable of plummeting the ignorance of women labour as an integral part of this industry. In developing countries like India, agriculture continues to absorb and employ female work force but fails to give them recognition of employed/hired labour. Women constituted $38 \%$ of the agricultural labour force in developing countries. It is also estimated that $45.3 \%$ of the agricultural labour force consists of women. But a large number of women have remained as "invisible workers". Since there has been concern expressed regarding the gap between women's actual economic participation and public perception of it several researchers have attempted to overcome this invisibility through gendered empirical research studies for using on gender analysis and gender roles. This piece of research is highlighting the trend of female participation in agriculture across various Indian states. The secondary data collated for the research is used to study the growth trend of the agricultural worker from 1961-2001. Analysis is done to categorize the states on their identical behaviour of participation in agriculture by hierarchical clustering of economically active female in agriculture based on measurements like coefficient of variation, compound growth rate and work participation rate.
\end{abstract}

Keywords: Work Participation rate, Economically Active Female, Compound Growth Rate, Hierarchical Clustering

\section{Introduction}

The advent of settled life happened with the beginning of agriculture when people started cultivating food for their livelihood. Agriculture is the vertical backbone of the country. Major part of the country's population earns its livelihood from agriculture. Our country has a wide and very old setting of agriculture of about 10 thousand years. At present in terms of agriculture production the country holds second position across the world. The agricultural production in India encompasses field crops, fruit crop, plantation crop, livestock, forestry, fishery etc. So overall it is a huge industry which recruits or engages $52 \%$ of overall manpower of India. The rural population of our country is mostly dependent on agricultural activity. Despite of the fact that there has been steady slump in the contribution of agriculture in country's GDP, Indian agriculture continues to remain the leading industry in the country contributing vastly in the socioeconomic growth of India. States like Punjab, Uttar Pradesh, Madhya Pradesh, Andhra Pradesh, Haryana, Bihar and West Bengal are the leading states in terms of agricultural contribution of the country followed by the rest. Thus agriculture in India is the key industry and in recent times with implementation and initiatives of various government policies, NGO's and private agencies immense growth is recorded in this industry. The scenario of agriculture has completely changed with change in time but from centuries one thing that didn't change is the visualization of women as key labour in this industry. Agriculture sector as a whole has developed and emerged immensely with the infusion of science and technology. But this latest emergence is not capable of plummeting the ignorance of women labour as an integral part of this industry. In developing countries like India, agriculture continues to absorb and employ $2 / 3^{\text {rd }}$ of the female work force but fails to give them recognition of employed labour. The female labour force in developing nations still faces the oppressive status of being majorly responsible for family and household maintenance. In addition to that their contribution of being a agriculture labour is suppressed under the status of family labour who work in farm in addition to her regular household chores. These problems of the rural women are further accentuated by the tribulations of illiteracy, underdevelopment, unemployment and poverty. Despite of the major productive women labor force in agriculture their needs and problems are somewhat ignored by the rural development initiatives. The multitasking potentiality of female labour bought significant propositions for agricultural productivity, rural production, economic vitality, household food security, family health, family economic security and welfare.

Many of the systematic studies identify the trends of working female labour in agriculture. Empirical studies were conducted and explained on gender roles and gender analysis. This piece of research will further highlight the trend of female participation in agriculture across various Indian states. Efforts were put to collate 
and categorize the states of identical behaviour in Indian agriculture by hierarchical clustering of economically active female in agriculture.

\section{Literature Review}

Singh and Vinay (2012) briefed in their working paper about the significance of female labour in agriculture and allied activities. They further stated that the role of women in agriculture as female labour is not highlighted in India. Despite of their presence in activities sowing, transplanting and post harvest operations they are considered as an invisible workers.

Damisa et.al (2007) highlighted in their study that despite of various social, economic and various other constraints women have high level participation in agriculture and they are very committed in their agricultural activity. Overall the level of involvement of women in farm decision making was found very medium. The extent of involvement and decision making in activities like intercultural operations is 48 percent in harvesting of crops 45.33 percent, storage of farm produce is 42.67 percent; 42.00 percent in sale of farm produce and in subsidiary occupation like animal husbandry and dairy business is 38.67 percent and financial management is 36 percent only ( Unati et.al, 2011).

Bala (2010) cited in his working paper regarding engagement and participation of women workers in almost all activities of agriculture but there is discrimination in wages even if they do same type of work as male labour. Further despite of their extensive and active involvement in agriculture of India, they are not considered for decision making in farm activities. Women participation in agriculture will be acknowledged when women farmer will actively participate to build and improve their knowledge and gain access to new and necessary information to make use of most of them in their farming activities. By linking the knowledge and information flow amongst women socio economic progress can be achieved (Dhaka et. al, 2012).

Farid et.al (2009) discussed the major role of women in farming \& non- farming activities especially in post harvest operations, homestead gardening, livestock and poultry rearing, selling labour etc. The primary need of women working or seeking employment in various agricultural and non -agricultural activities is to meet the family needs and to enhance the family income.

\section{Objectives}

Taking into consideration the productive and optimistic participation of women in agriculture the present study "Analysis of Women Participation in Indian Agriculture" has been undertaken with the following specific objectives

a. To study the trend of women participation in agriculture as cultivator and agricultural labourers in Indian states.

b. To study the homogeneity/ identical behaviour of women participation in agriculture in each state.

The entire study has been done considering the two specific objectives. To accomplish the requirement of the research work secondary data has been recorded. For the first step the data set is collected from Census of India2001 and Statistical Report on profile of women labour -2005-06. The entire population has been classified into three main categories i.e. Main, Marginal and Non - Workers. They are again further divide into Cultivators, Agricultural Labourers, Household Industry and Other workers depending on nature of their works. A person is considered as cultivator if he or she was engaged either as employer, single worker or family worker in cultivation of land owned or held from government or held from private persons or institutions for payment in money, kind or share of crop. Cultivation included supervision or direction of cultivation and a person who worked in another person's land for wages in cash, kind or share was regarded as an agricultural labourer. Such a person had no risk in cultivation but merely worked in another person's land for wages. An agricultural labourer had no right of lease or contract on land on which he worked.

\section{a. To study the trend of women participation in agriculture as cultivator and agricultural labourers in Indian states}

Women are regarded as the backbone of the rural panorama. About 75 percent of the Indian female populations are from rural families, who belonged to the small and marginal farmers and landless agricultural labourers (Census of India, 1991). The association of women in agriculture is an age-old practice. Since then there has been concern expressed regarding the gap between women's actual economic participation and public perception of it. Women constitute about half of the world's population, their labour contributes to 60 percent of the hours worked, contributing up to 30 percent of official hours. Yet women receive only 10 per cent of the world's income and own less than one per cent of the world's property (Gupta, 1987). Over the years, there is a gradual realization of the key role of women in agricultural development and their vital contribution in the field of agriculture, food security, horticulture, processing, nutrition, sericulture, fisheries, and other allied sectors. Women form the backbone of agriculture, in India, comprises the majority of agricultural labourers; women have been putting in labour not only in terms of physical output but also in terms of quality and efficiency. 
Women are critical to the well-being of farm households. Perhaps, ironically, it is because women have so many responsibilities that they have been over-looked by agriculturalists and policy makers - it has been more convenient to label men as farmers and women as child raisers and cooks. In truth, women are involved in all aspects of agriculture, from crop selection to land preparation, to seed selection, planting, weeding, pest control, harvesting, crop storage, handling, marketing, and processing. Whatever the reason for this neglect, the importance of developing farming technologies relevant to women has only recently been recognized. Rural Women form the most important productive work force in the economy of majority of the developing nations including India. Agriculture, the single largest production endeavor in India, contributing 25 percent of GDP, is increasingly becoming a female activity. Agriculture sector employs $4 / 5^{\text {th }}$ of all economically active women in the country. 48 percent of India's self-employed farmers are women. There are 75 million women engaged in dairying as against 15 million men and 20 million in animal husbandry as compared to 1.5 million men. More than simply supplying labour, women possess detailed knowledge of agriculture and use of plant and plant product for food, medicine and animal feed. Women today are central to the selection, breeding, cultivation, preparation \& harvest of food crops. Apart from their pivotal role in cultivation of staple crops, they are primarily responsible for the production of secondary crops such as pulses and vegetables which are often the only source of nutrition available to their families. Women farmers also often possess unique knowledge about fish farming and handle most of the work associated with it. Beyond the conventional market-oriented narrower definition of 'productive workers', almost all women in rural India today can be considered as 'farmers' in some sense, working as agricultural labour, unpaid workers in the family farm enterprise, or combination of the two. Thus, Rural India is witnessing a process which could be described as Feminization of Agriculture. The table below (Table 1) explains the scenario of female workers across Indian States and also visualizes the percentage of women involved in agriculture as primary occupation and the rest shows that percentage that generates their income from non- agricultural activities like household industry, services etc. It can be clearly indicated that across all the states considered for our study women majorly generates their income through agriculture and agricultural activities. Exceptions were there like Punjab, Kerala, and West Bengal where women were comparatively involved in non agricultural activities.

Table 1: State-wise trend of Women Participation in Agricultural \& Non - Agricultural Activities

\begin{tabular}{|c|c|c|c|}
\hline State & Total Female Workers & $\begin{array}{c}\text { Percent of Female } \\
\text { workers in Agriculture }\end{array}$ & $\begin{array}{l}\text { Percent of Female workers in } \\
\text { Non- Agricultural Activities }\end{array}$ \\
\hline HIMACHAL PRADESH & 630521 & 82.47 & 17.53 \\
\hline MANIPUR & 229137 & 55.59 & 44.41 \\
\hline NAGALAND & 279166 & 82.66 & 17.34 \\
\hline ANDHRA PRADESH & 9585381 & 73.44 & 26.56 \\
\hline RAJASTHAN & 4595570 & 81.07 & 18.93 \\
\hline MADHYA PRADESH & 5046293 & 79.45 & 20.55 \\
\hline KARNATAKA & 5467914 & 61.11 & 38.89 \\
\hline TAMIL NADU & 7454473 & 59.30 & 40.70 \\
\hline MAHARASHTRA & 10331758 & 74.53 & 25.47 \\
\hline GUJARAT & 3544508 & 57.12 & 42.88 \\
\hline ORISSA & 1584529 & 60.47 & 39.53 \\
\hline TRIPURA & 170238 & 52.78 & 47.22 \\
\hline ASSAM & 1265065 & 42.47 & 57.53 \\
\hline PUNJAB & 1409704 & 24.51 & 75.49 \\
\hline BIHAR & 3541857 & 83.56 & 16.44 \\
\hline WEST BENGAL & 3528612 & 32.62 & 67.38 \\
\hline UTTAR PRADESH & 4999389 & 65.87 & 34.13 \\
\hline KERALA & 1776280 & 21.27 & 78.73 \\
\hline
\end{tabular}


Fig 1: State-wise Women Participation in Agricultural \& Non - Agricultural Activities

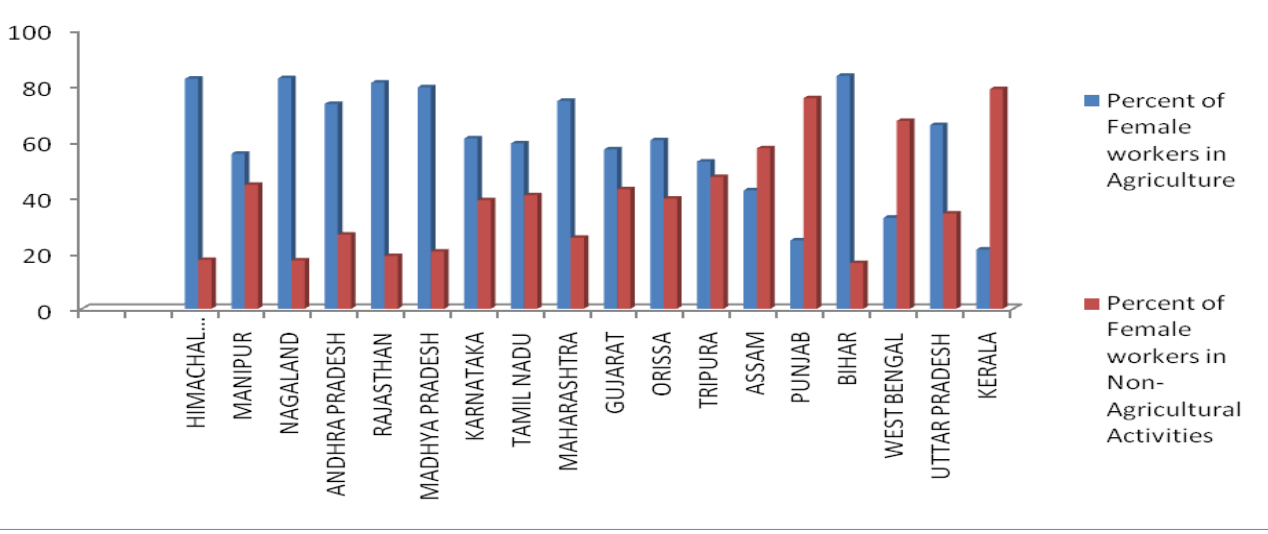

The graph (Figure 1) below also represents women involvement in agriculture and non - agricultural activities across diverse states of India.

Table.2 Compound Growth Rate (CGR) of Cultivators and Agricultural labours of India

\begin{tabular}{|l|r|r|r|r|}
\hline \multirow{2}{*}{\multicolumn{1}{c|}{ STATES }} & \multicolumn{2}{c|}{ CULTIVATORS } & \multicolumn{2}{c|}{ AG. LABOUR } \\
\cline { 2 - 5 } & MALE CGR & FEMALE CGR & MALE CGR & FEMALE CGR \\
\hline Andhra Pradesh & 1.002 & 0.996 & 1.015 & 1.010 \\
\hline Kerala & 0.989 & 0.973 & 1.007 & 1.039 \\
\hline Tamil Nadu & 0.994 & 0.994 & 1.016 & 1.014 \\
\hline Karnataka & 1.004 & 0.994 & 1.016 & 1.015 \\
\hline Gujrat & 1.006 & 0.989 & 1.022 & 1.012 \\
\hline Maharashtra & 1.005 & 1.000 & 1.013 & 1.056 \\
\hline Madhya Pradesh & 1.001 & 0.987 & 1.015 & 1.011 \\
\hline Punjab & 0.989 & 0.953 & 1.012 & 1.020 \\
\hline Uttar Pradesh & 1.003 & 0.987 & 1.017 & 0.999 \\
\hline Rajasthan & 1.008 & 1.003 & 1.021 & 1.016 \\
\hline Himachal Pradesh & 1.011 & 1.008 & 1.025 & 1.019 \\
\hline Bihar & 0.997 & 0.972 & 1.020 & 1.003 \\
\hline Orissa & 0.999 & 0.980 & 1.013 & 1.015 \\
\hline West Bengal & 1.001 & 0.992 & 1.019 & 1.018 \\
\hline Assam & 1.000 & 0.981 & 1.024 & 1.040 \\
\hline Nagaland & 1.019 & 1.016 & 1.037 & 1.026 \\
\hline Manipur & 1.004 & 1.004 & 1.063 & 1.058 \\
\hline Tripura & 1.000 & 0.990 & 1.030 & 1.050 \\
\hline
\end{tabular}

The growth in any period is not independent of the value of the variable in the previous period. The concept of Compound Growth Rate (CGR) is for better estimation which is calculated for all the states of India which is calculated as

$$
\mathrm{Y}_{\mathrm{t}}=\mathrm{Y}_{0}(1+\mathrm{r})^{\mathrm{t}} \text {. }
$$

i.e. $\log Y_{t}=\log Y_{o}+t \log (1+r)$

Where, $\mathrm{r}$ is the compound rate of growth is calculated by the equation $\mathrm{r}=\left(\right.$ Antilog $\left.\mathrm{b}_{1}-1\right) * 100$.

The table (Table 2) depicted the Compound Growth Rate (CGR) for male and female. The CGR illustrate how much the population grew on average per year, over the multiple year periods. The CGR is shown for cultivators and agricultural Labourers for all the states of India from the period 1961-2001. The CGR is almost uniform for all the states showing very slight changes in few states which show a bit higher CGR than the rest. States like Nagaland, Himachal Pradesh and Rajasthan shows good growth rate in case of male cultivators. But Nagaland shows highest CGR in case of both male and female cultivators. The States like Himachal Pradesh, Manipur and Rajasthan illustrate a fine Compound Growth Rate for female cultivators.

In case of both Agricultural Labourers male \& female, Manipur shows the highest and Kerala shows the lowest Compound Growth Rate (CGR) for male agricultural labour and the lowest CGR for female agricultural labour 
is of Bihar. The female agricultural labours of Maharashtra, Tripura and Kerala demonstrate a good compound growth rate also the male agricultural labour of Nagaland, Tripura, Himachal Pradesh and Assam shows good CGR.

b. To study the homogeneity/ identical behaviour of women participation in agriculture in each state.

Efforts were made to get the states of identical behaviour of women participation in Indian agriculture in each of the considered states. To identify the classification among the states and to form groups of states following similar pattern based on several measurements like Coeffient of variation (\%), Compound Growth Rate (CGR) and Female Work Participation Rate (WPR) cluster analysis is being made. The available data is used to form clusters considering the hypothetical distance i.e. Euclidean distance between the pairs of eighteen states. For female population corresponding Dendrogram are presented in Figure 2 below been displayed by Dendrogram considering average linkage between the groups

Figure 2: Dendrogram of Female Agricultural Population Rescaled Distance Cluster Combine

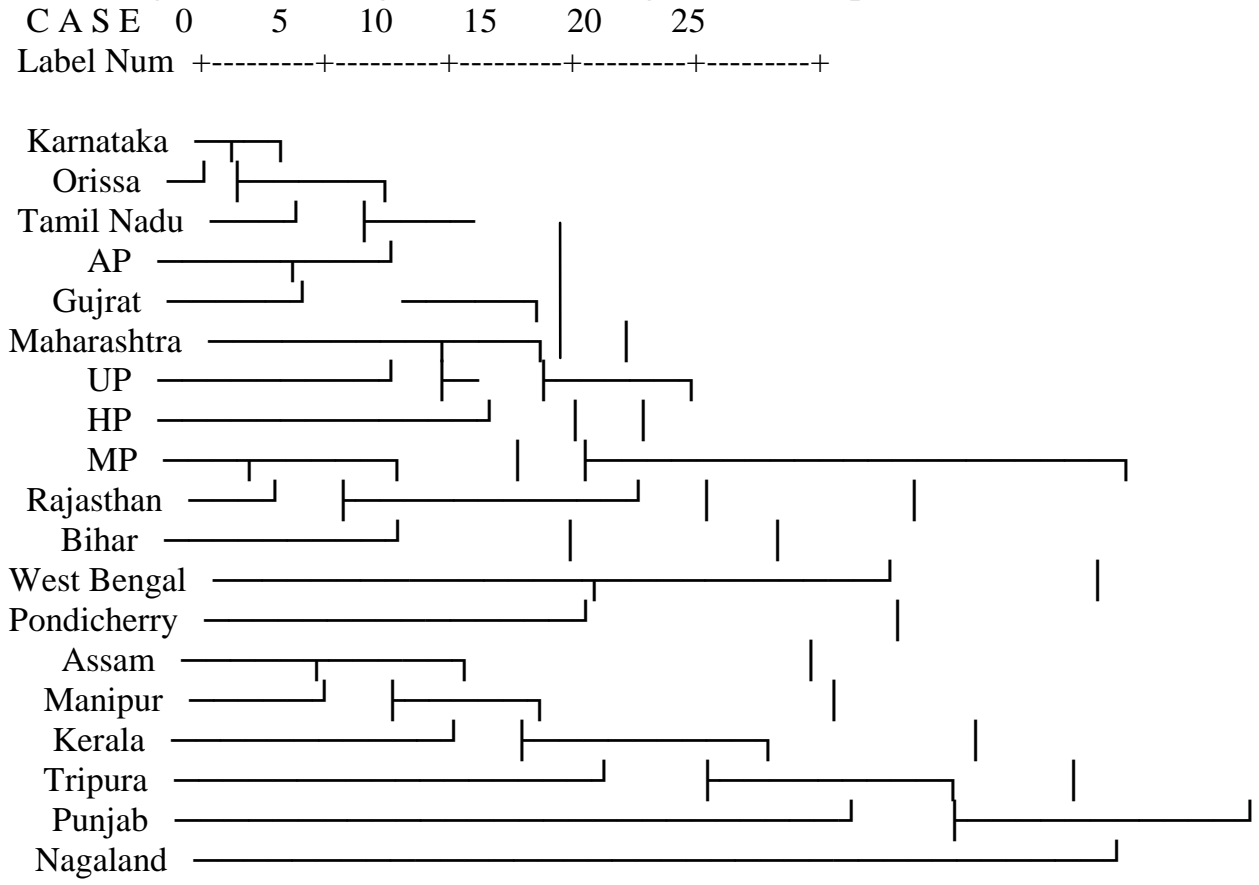

For classifying the female agricultural population considering the measurments like Coeffient of variation (\%), Compound Growth Rate (CGR) and Work Participation Rate (WPR). Homogenous groups are formed which are presented in Dendrogram in Figure 2. The Dendrogram analysis at five rescaled distance here shows six different clusters. The clusters formed are listed below

a) Karnataka , Tamil Nadu and Orissa.

b) Andhra Pradesh, Gujrat.

c) Maharashtra, Uttar Pradesh and Himachal Pradesh.

d) Madhya pradesh, Rajasthan and Bihar.

e) West Bengal and Pondicherry.

f) Assam, Manipur, Kerala, Tripura, Punjab and Nagaland.

All these states emerged together forming six different clusters showing their homogeneity and identical behaviour in women participation in agriculture.

\section{Conclusion:}

The purpose of this study is to analyse the women participation in agriculture across diverse Indian states based on secondary data source. Efforts were made to systematically collate the data and analyse the trend of women participation in each state. The study clearly depicts active involvement and participation of women in the agricultural sector in almost all the states with few exceptions like Kerela, Punjab and West Bengal where women are actively participating in non-agricultural activities which includes house-hold industry, service sector etc. The growth rate trend illustrates how much the population grew on average per year, over the multiple year periods. It is almost uniform for all the states showing very slight changes in few states which shows a bit higher growth rate than the rest. The cluster analysis further grouped the considered states as per 
their identical behaviour of participation. Thus the entire work can be concluded with the facts that women participation in agriculture is increasing with time and women are now acknowledged with the status of "agricultural worker". Though discrimination of wages and in working status still prevails for women labour but due to implementation of various policies and initiatives taken by government the invisibility of women as an agricultural worker is plummeting and will further diminish in future.

\section{References:}

[1]. Bala. N (2010), "Selective discrimination against women in Indian Agriculture - A Review" Agricultural Reviews. 31 (3): 224 228.

[2]. Census of India, (1981) Series India, Primary Census Abstract, General Population, Part 11B (i), pp.7-8.

[3]. Damisa, R. Samndi and M. Yohana(2007). "Women Participation in Agricultural Production- A probit Analysis" Journal of Applied Sciences. 7(3): 412-416.

[4]. Dhaka et. al (2012), "Constraints in Knowledge and Information Flow amongst Farm Women" International Journal of Agriculture, Environment \& Biotechnology. 5(2): 167-170.

[5]. Farid et.al (2009), "Nature and extent of rural women's participation in agricultural and non-agricultural activities" Agricultural Science Digest. 29 (4): 254-259.

[6]. Gupta, R. (1987), "Role of women in economic development".Yojana 31(8): 28-32.

[7]. Johnson. R.A. and D.W. Wichern. (2000). Applied Multivariate Statistical Analysis. Pearson Education Asia.

[8]. Singh and Vinay (2013). "Gender participation in Indian agriculture: An ergonomic evaluation of occupational hazard of farm and allied activities" International Journal of Agriculture, Environment \& Biotechnology. 6(1): 157-168.

[9]. Unnati. A, G.S Ankush and A. V. Mande (2012) "Extent of participation of farm women in Decision making” Journal of Dairying Foods \& Home Sciences. 31 (1): $72-74$ 